\title{
CRESCIMENTO E PRODUTIVIDADE DE CAFEEIROS NA REGIÃO DO ALTO PARANAÍBA EM FUNÇÃO DO TIPO DE PODA E USO DE DESBROTA
}

\author{
Gleice Aparecida Assis ${ }^{* 1}$, Lucas Rafael Souza Silva², William Eduardo Reis Martins², Fábio Janoni \\ Carvalho ${ }^{3}$, Patrícia Santos Pires ${ }^{2}$ \\ ${ }^{1}$ Docente da Universidade Federal de Uberlândia - Campus Monte Carmelo, Monte Carmelo - MG \\ ${ }^{2}$ Discente do curso de Agronomia da Universidade Federal de Uberlândia - Campus Monte Carmelo, Monte Carmelo - MG \\ ${ }^{3}$ Engenheiro Agrônomo do Instituto Federal do Triângulo Mineiro, Uberaba - MG \\ "Autora para correspondência: Gleice Aparecida de Assis, gleice@ufu.br
}

\begin{abstract}
RESUMO: Objetivou-se com esse trabalho avaliar a recuperação de plantas por meio de seu crescimento vegetativo e produtividade, submetidas a diferentes tipos de poda e condução com desbrota manual e química. Verificou-se que as plantas conduzidas com desbrota manual apresentaram um maior diâmetro de copa e comprimento de ramo quando comparado com as plantas em que foi realizada desbrota química. Já para número de nós do ramo plagiotrópico não foi detectada diferença significativa. As plantas conduzidas com desbrota química apresentaram sintomas de clorose e estreitamento do limbo foliar e alguns casos de superbrotamento 30 dias após a desbrota. Com relação às características vegetativas avaliadas, verificou-se que podas menos drásticas que eliminaram pequenas partes dos ramos plagiotrópicos e ortotrópico do cafeeiro apresentaram recuperação mais rápida quando comparada com as mais drásticas, onde a maior parte dos ramos plagiotrópicos e ortotrópicos são eliminados, ocasionando um efeito danoso na estrutura vegetativa da planta. Não foram observadas diferenças com relação à produtividade para as podas e conduções adotadas. O maior rendimento de café colhido na planta/ café beneficiado foi obtido nos tratamentos com poda do tipo decote com esqueletamento e decote com desponte. Plantas decotadas apresentaram maior porcentagem de frutos no estádio cereja quando comparada com as demais podas utilizadas.
\end{abstract}

PALAVRAS-CHAVE: Coffea arabica L, condução parte aérea, desenvolvimento vegetativo, rendimento.

\section{COFFEE PLANT GROWTH AND PRODUCTIVITY IN ALTO PARANAÍBA REGION BASED ON PRUNING TYPE AND ON THINNING}

\begin{abstract}
The aim of the current study is to evaluate the recovery of plants subjected to different pruning types, as well as to different conductions through manual and chemical thinning, based on their vegetative growth and yield. Conducted plants subjected to manual thinning showed larger crown diameter and longer branches than plants subjected to chemical thinning. On the other hand, the number of nodes in the plagiotropic branch did not show significant difference between manual and chemical thinning. Conducted plants subjected to chemical thinning showed chlorosis symptoms and leaf blade narrowing, besides some secondary bulb-growth cases 30 days after thinning. With respect to the herein evaluated vegetative characteristics, plants subjected to non-severe pruning procedures, based on removing small parts of the plagiotropic and orthotropic branches of coffee trees, presented faster recovery than plants subjected to severe pruning. Most plagiotropic and orthotropic branches were removed during severe pruning and generated a damaging effect on the vegetative structure of plants. Plants subjected to the herein adopted pruning and conduction procedures did not show yield differences. Plants subjected to the following pruning types required lower coffee volume to produce one bag of processed coffee: "decote" (pruning orthotropic branches $2.5 \mathrm{~m}$ above the ground) along with "esqueletamento" (pruning all plagiotropic branches $0.3 \mathrm{~m}$ away from the main trunk) and "decote" along with "desponte" (pruning plagiotropic branches $0.7 \mathrm{~m}$ away from the main trunk). "Decote" recorded higher coffee-fruit rate than the other pruning types used in the current study.
\end{abstract}

KEYWORDS: COFFEA ARABICA L, SHOOT CONDUCTION, VEGETATIVE DEVELOPMENT, GRAIN YIELD. 


\section{INTRODUÇÃO}

A cafeicultura é considerada uma das principais culturas do país. O Brasil se encontra na posição de maior produtor e exportador mundial, sendo que a cafeicultura nacional ocupa uma área de 1,9 milhão de hectares, com uma produção estimada para 2018 entre 54 e 58,5 milhões de sacas beneficiadas (Conab, 2018).

O estado de Minas Gerais é responsável por $43 \%$ da produção nacional, sendo o Cerrado Mineiro responsável por 13,7\% deste total (Conab, 2018). Essa região tem sua importância comprovada na cafeicultura nacional, pois foi a primeira no país a receber o selo de Denominação de Certificação de Origem do café produzido.

A tradição da cafeicultura nacional durante um grande período foi o cultivo de Coffea arabica L. em livre crescimento, sem o uso de podas. Porém, com a adoção de cultivares altamente produtivas com grande vigor vegetativo e o emprego de técnicas de manejo para 0 aumento da produtividade, surgiram problemas de desgaste nas lavouras ao longo das safras.

Com intuito de recuperar o cafeeiro sem a sua erradicação e novo plantio, diversos estudos sobre 0 uso de podas no cafeeiro estão sendo conduzidos. Esse manejo tem a finalidade de eliminar partes das plantas que perderam ou diminuíram a produção, cuja capacidade de recuperação natural seja praticamente nula (Thomaziello e Pereira, 2008).

Alguns benefícios do uso da poda no cafeeiro são citados por Carvalho et al. (2010) como o aumento dos ramos produtivos em plantas debilitadas, correção da arquitetura da planta, recuperação de cafeeiros atingidos por geadas, chuva de granizo e seca, facilidade na colheita mecanizada, arejamento da lavoura e auxílio no controle de pragas e doenças.

A poda no cafeeiro deve ser aplicada somente quando existe sua real necessidade, levando em consideração algumas características da lavoura como o bom estande de plantas, apresentar histórico de boas produtividades e ser um material genético que responda à poda. Quando realizada em lavouras que não apresentem tais características, pode proporcionar a não renovação dos ramos produtivos resultando em perdas na produtividade.

As podas em lavouras cafeeiras podem ser agrupadas em dois tipos principais: podas drásticas, como recepa e o esqueletamento, e podas leves como o decote, desponte e podas de limpeza (Matiello et al., 2007).

Esqueletamento é um tipo de poda onde se realiza o corte dos ramos plagiotrópicos a uma distância de 20 a $30 \mathrm{~cm}$ do ramo ortotrópico. 0 desponte também é uma poda lateral semelhante ao esqueletamento, com a diferença que o corte é realizado a uma distância em torno de 60 a $70 \mathrm{~cm}$ do ramo ortotrópico (Thomaziello e Pereira, 2008)

Decote é uma poda alta que resulta na eliminação da parte superior da copa do cafeeiro, sendo indicada para lavouras em vias de fechamento com boa ramificação lateral no terço inferior das plantas (Matiello et al., 2010).

Após a realização da poda, o cafeeiro tende a apresentar grande quantidade de ramos "ladrões". Com o intuito de eliminar esses ramos se realiza a desbrota, podendo ser de forma manual ou mecânica. A desbrota química, com o uso do herbicida glifosato, pode ser uma alternativa viável para inibir o crescimento de ramos improdutivos e que competem com os ramos plagiotrópicos pelos assimilados (Matiello et al., 2010).

Objetivou-se com este trabalho avaliar a recuperação de plantas cultivar Mundo Novo IAC 3764 por meio do crescimento vegetativo e produtividade, submetidas a diferentes tipos de poda e condução com desbrota manual e química na região do Alto Paranaíba.

\section{MATERIAL E MÉTODOS}

0 experimento foi instalado no dia 12 de setembro de 2015, na fazenda Santa Fé, situada no município de Romaria, região do Alto Paranaíba, estado de Minas Gerais, a uma altitude de 945 metros, latitude $18^{\circ} 52^{\prime} 26^{\prime \prime} \mathrm{S}$ e longitude $47^{\circ} 36^{\prime} 14,5^{\prime \prime} \mathrm{W}$. O clima é classificado segundo Köppen como Aw, clima tropical úmido de savana, onde a época mais seca coincide com inverno, sendo a precipitação do mês mais seco nesta estação inferior a $60 \mathrm{~mm}$ e precipitação média anual de $1200 \mathrm{~mm}$. A temperatura média do mês mais frio do ano é superior a $18^{\circ} \mathrm{C}$, com média anual de $22^{\circ} \mathrm{C}$ (Sá Junior, 2009).

O plantio da cultivar Mundo Novo IAC 376-4 foi efetuado em dezembro de 2004, com espaçamento de 4,0 metros entre linhas e 0,7 metro entre plantas, manejada com irrigação por gotejamento com vazão dos emissores de 2,3 L h-1 e espaçamento entre emissores de 0,7 metro. 
A adubação do experimento foi realizada conforme recomendação de Matiello et al. (2010) considerando a necessidade do cafeeiro para vegetação e produção. No primeiro ano após a poda foi considerado o potencial produtivo da lavoura podada e os teores de nutrientes no solo, adotando metade da dose no primeiro ano (ano de crescimento) e sendo adotada dose total no segundo ano (ano de produção).

Os controles fitossanitários foram realizados conforme necessidade da cultura, de forma semelhante em todos os tratamentos.

0 experimento foi conduzido delineamento em blocos casualizados com quatro repetições em esquema fatorial de parcelas subdivididas no tempo, sendo três tipos de poda (Decote a 2,5 m, Decote a 2,5 m com Desponte e Decote a 2,5 m com Esqueletamento) e dois sistemas de condução dos brotos (desbrota manual e desbrota química) os fatores da parcela, e os dias após a poda $(90,150,210,270$ e 330 dias $) 0$ fator de subparcela, totalizando 24 parcelas, com área total de 1.008 m2 e área útil de 604,8 m2. As parcelas foram compostas por 15 plantas, sendo nove úteis e três plantas de bordadura em cada extremidade.

A poda foi realizada de forma mecanizada no dia 12/09/2015. Após a realização dessa prática cultural, foi acompanhado o crescimento dos brotos e no mês de fevereiro de 2016, quando os mesmos atingiram entre 15 e 20 centímetros de altura, foi realizada a desbrota.

A desbrota manual foi realizada mediante 0 arranquio dos ramos "ladrões" localizados ao longo de todo o ramo ortotrópico da planta.

Para a desbrota química foi aplicado o herbicida glifosato-sal de potássio diluído, na concentração de $2 \%$ do princípio ativo conforme recomendação de Matiello et al. (2010). Para a aplicação foi utilizado um pulverizador costal, sendo direcionada somente aos ramos "ladrões" do terço superior do ramo ortotrópico da planta. Os demais ramos "ladrões" localizados no terço médio e inferior do ramo ortotrópico da planta foram arrancados de forma manual.

As medidas de crescimento foram realizadas bimestralmente com início em dezembro de 2015, noventa dias após a poda, totalizando cinco épocas de avaliação: 90, 150, 210, 270 e 330 dias após a poda. Foram analisadas as seguintes características:

- Diâmetro de copa $(\mathrm{cm})$ : medido no sentido transversal à linha de plantio, considerando- se a extensão do ramo plagiotrópico de maior dimensão em cada planta, com auxílio de uma régua graduada.

- Número de nós do ramo plagiotrópico: obtido pela contagem do número de nós nos ramos plagiotrópicos que surgiram após a poda, no terço superior, médio e inferior, em ambos os lados das plantas.

- Comprimento do ramo plagiotrópico $(\mathrm{cm})$ : medido com auxílio de uma fita métrica graduada nos mesmos ramos plagiotrópicos que foram contados o número de nós, no terço superior, médio e inferior, em ambos os lados das plantas.

Com intuito de avaliar o rendimento da desbrota manual, foi quantificado o tempo gasto em segundos em cada parcela para retirada dos ramos "ladrões" ao longo de todo ramo ortotrópico (tratamentos sem desbrota química) e somente no terço médio e inferior do ramo ortotrópico (tratamentos com desbrota química). A desbrota manual foi realizada no mês de fevereiro de 2016 por dois trabalhadores, logo após a realização da desbrota química no terço superior das plantas.

A produtividade na safra 2017 foi obtida por meio da colheita realizada por meio de derriça manual no pano iniciada quando o percentual dos frutos verdes estava entre $10 \%$ e $15 \%$. No dia da colheita, foi mensurado o volume $(L)$ de frutos em cada parcela e retirada uma amostra de $10 \mathrm{~L}$ de cada repetição. As amostras foram acondicionadas em peneiras, sendo revolvidas várias vezes ao longo do dia para uma secagem homogênea, até atingir umidade de beneficiamento (entre $11 \%$ e 12\%). Posteriormente foi determinada a massa, o volume e a umidade do café beneficiado. Os dados obtidos em todas fases do processo foram utilizados no cálculo de produtividade (sacas de $60 \mathrm{~kg}$ de café beneficiado por hectare) e rendimento (volume de frutos necessário para produzir uma saca de $60 \mathrm{~kg}$ de café)

Para determinação dos estádios de maturação do volume total de café colhido, foi retirada uma amostra representativa de $0,5 \mathrm{~L}$ de cada parcela experimental para separação dos mesmos, em frutos chumbinho, verde, verde-cana, cereja, passa e seco. 
Os dados foram submetidos à análise de variância pelo software SISVAR (Ferreira, 2008) após 0 atendimento das pressuposições de normalidade dos resíduos, homogeneidade de variâncias e aditividade de blocos. Quando diferença significativa foi detectada, as variáveis foram ajustadas à análise de regressão (Época de avaliação) ou comparadas pelo Teste de Tukey (Poda e Condução) ao nível de 5\% de probabilidade.

\section{RESULTADOS E DISCUSSÃO}

\section{Características de crescimento}

Durante o período estudado houve efeito significativo da condução dos brotos nas características vegetativas diâmetro de copa e comprimento do ramo plagiotrópico (Tabela 1). Para número de nós do ramo plagiotrópico não foi verificado efeito significativo a $5 \%$ de probabilidade.

Tabela 1. Resumo da análise de variância para características vegetativas de plantas da cultivar Mundo Novo submetidas a três tipos de poda e dois sistemas de condução dos brotos na Região do Alto Paranaíba, 2016

\begin{tabular}{|c|c|c|c|c|}
\hline \multirow[b]{2}{*}{ FV } & \multirow[b]{2}{*}{ GL } & \multicolumn{3}{|c|}{ Quadrado médio } \\
\hline & & Diâmetro de copa $(\mathrm{cm})$ & $\begin{array}{l}\text { Comprimento do ramo } \\
\text { plagiotrópico }(\mathrm{cm})\end{array}$ & $\begin{array}{c}\text { Número de nós do ramo } \\
\text { plagiotrópico }\end{array}$ \\
\hline Bloco & 3 & 12,47 & 159,13 & 10,32 \\
\hline Poda (P) & 2 & $37647,97^{* *}$ & $58,10^{\text {ns }}$ & $27,15^{* *}$ \\
\hline Condução (C) & 1 & $1778,47^{\star}$ & $179,49^{*}$ & $5,66^{n s}$ \\
\hline $\mathrm{P} \times \mathrm{C}$ & 2 & $301,86^{n s}$ & $24,06^{n s}$ & $2,23^{\text {ns }}$ \\
\hline Erro 1 & 6 & 174,22 & 26,36 & 2,15 \\
\hline Época (E) & 4 & $10795,90^{* *}$ & $1276,79^{* *}$ & $88,97^{* *}$ \\
\hline$E \times P$ & 8 & $187,95^{*}$ & $51,75^{*}$ & $1,59^{*}$ \\
\hline $\mathrm{E} \times \mathrm{C}$ & 4 & $86,21^{n s}$ & $5,24^{\text {ns }}$ & $0,13^{\text {ns }}$ \\
\hline $\mathrm{E} \times \mathrm{P} \times \mathrm{C}$ & 8 & $53,87^{\text {ns }}$ & $4,92^{\text {ns }}$ & $0,26^{n s}$ \\
\hline Erro 2 & 81 & 84,35 & 6,29 & 0,34 \\
\hline CV $(\%)$ & & 4,72 & 11,20 & 9,39 \\
\hline Média & & 194,40 & 22,40 & 6,23 \\
\hline
\end{tabular}

ns Não significativo, ${ }^{*}$ Significativo a $1 \%,{ }^{*}$ Significativo a $5 \%$ de probabilidade pelo teste $\mathrm{F}$.

Analisando a interação entre a época de avaliação e o tipo de poda foi observado efeito significativo em todas as características vegetativas avaliadas $(P<0,05)$. As demais interações não apresentaram efeito significativo a $5 \%$ de probabilidade para nenhuma das características vegetativas.

Com relação ao diâmetro de copa e comprimento do ramo plagiotrópico houve diferença significativa entre o sistema de condução dos brotos manual e químico ao nível de $5 \%$ de probabilidade. As plantas conduzidas com desbrota manual apresentaram maior diâmetro de copa e comprimento de ramo quando comparados com as plantas em que se realizou desbrota química. Já para a variável número de nós do ramo plagiotrópico não foi detectada diferença significativa (Tabela 2).

Tabela 2. Avaliação das características vegetativas de plantas da cultivar Mundo Novo submetidas a dois sistemas de condução dos brotos na Região do Alto Paranaíba, 2016

\begin{tabular}{cccc}
\hline & \multicolumn{3}{c}{ Médias } \\
\cline { 2 - 4 } Condução dos brotos & Diâmetro de Copa $(\mathrm{cm})$ & $\begin{array}{c}\text { Comprimento do ramo plagiotrópico } \\
(\mathrm{cm})\end{array}$ & Número de nós do ramo plagiotrópico \\
\hline Desbrota manual & $198,24 \mathrm{a}$ & $23,62 \mathrm{a}$ & $6,44 \mathrm{a}$ \\
Desbrota química & $190,54 \mathrm{~b}$ & $21,18 \mathrm{~b}$ & $6,01 \mathrm{a}$ \\
\hline
\end{tabular}

Médias seguidas pela mesma letra na coluna não diferem entre si pelo teste $\mathrm{F}$ ao nível de $5 \%$ de probabilidade. 
As plantas conduzidas com desbrota química apresentaram sintomas de clorose e estreitamento do limbo foliar e alguns casos de superbrotamento 30 dias após a realização da desbrota química. Esses sintomas foram mais pronunciados nas plantas em que foi realizada a poda do tipo esqueletamento. Segundo França et al. (2010a), a clorose foliar ocorre devido a menor síntese de clorofila, pois o glifosato impede de modo indireto a sua formação pelos efeitos prejudiciais na síntese de ácido aminolevulínico (ALA) um precursor da biossíntese de clorofila.

Matiello e Ferreira (2015), estudando o efeito da desbrota química em Coffea canephora Pierre, obtiveram resultados contrastantes em relação aos do presente trabalho, onde não detectaram sintoma visual de intoxicação das plantas em que se realizou a desbrota química. A ausência de intoxicação dessas plantas pode ser justificada devido ao $C$. canephora ser uma espécie mais robusta, o que possivelmente confere ao mesmo maior tolerância ao glifosato quando comparado com C. arabica.

Um menor crescimento em diâmetro de copa e comprimento de ramo nas plantas em que se realizou a desbrota química pode ter sido ocasionado pela concentração de glifosato na calda, podendo ter intoxicado as plantas. Em estudo realizado por
França et al. (2010b), na aplicação de glifosato para controle de plantas daninhas no cafeeiro aos 130 dias após o transplantio, foi observado uma redução do crescimento em altura do cafeeiro de acordo com o aumento da dose por hectare de 57,6 g ha-1 a 460,8 g ha-1 de glifosato.

\section{Diâmetro de copa}

Analisando-se o diâmetro de copa das plantas, verificou-se efeito significativo do desdobramento tipos de poda em todas as épocas avaliadas $(P<0,05)$. 0 diâmetro de copa do cafeeiro ajustou-se ao modelo linear em todos os tratamentos com coeficiente de determinação superiores a 0,98 (Figura 1).

Aos 90 dias após a poda foi possível observar que as plantas decotadas apresentaram maior diâmetro de copa quando comparado com as plantas submetidas ao decote com desponte e decote com esqueletamento. Os mesmos resultados foram observados até 150 dias após a poda. Já aos 210 dias após a poda não foram observadas diferenças entre plantas decotadas e decotadas com desponte, havendo diferença quando comparado ao decote com esqueletamento. Esses resultados permaneceram até a última época de avaliação (Figura 1).

Figura 1. Diâmetro de copa de plantas da cultivar Mundo Novo submetidas a três tipos de poda na Região do Alto Paranaíba, 2016.

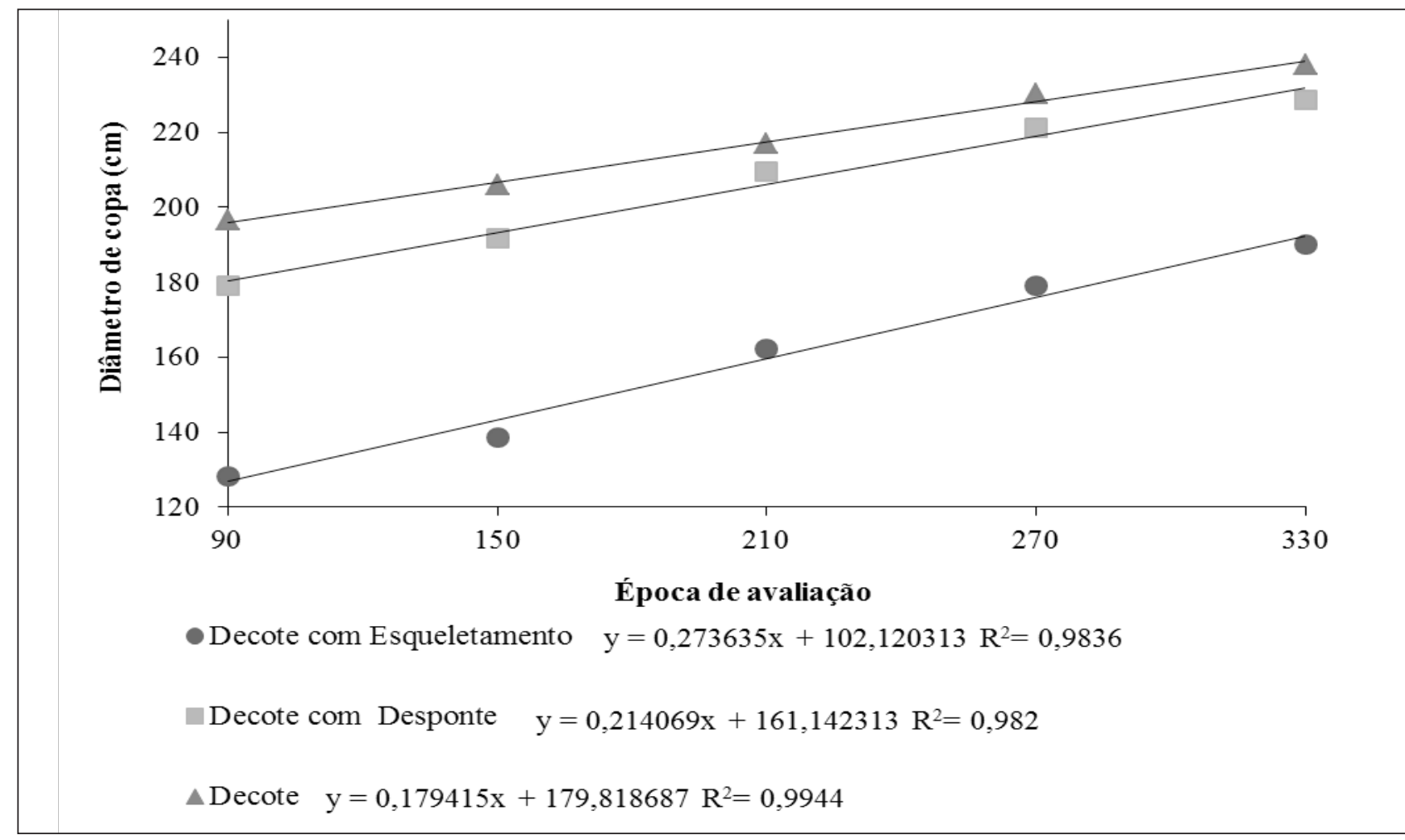


É possível estimar pela inclinação das retas ajustadas que a cada 100 dias houve um crescimento em diâmetro de copa de $17,94 \mathrm{~cm}, 21,40 \mathrm{~cm}$ e 27,36 $\mathrm{cm}$, respectivamente, para as podas decote, decote com desponte e decote com esqueletamento.

As plantas decotadas e esqueletadas apresentaram menor diâmetro de copa em todas as épocas estudadas. Este fato pode indicar que o uso dessa poda promoveu menor recuperação das plantas quando comparado com as plantas em que foi realizado 0 decote isolado ou decote com desponte. Essa menor recuperação poderá afetar a produtividade dessas plantas, devido às mesmas não possuírem, durante a fase de iniciação floral, ramos maduros para que ocorra a iniciação floral e as demais fases fenológicas da produção (Pereira et al., 2007).

O diâmetro de copa semelhante das plantas decotadas e decotadas com desponte aos 210 dias após a poda pode indicar que podas menos drásticas mantém as plantas com maior reserva de carboidratos nas folhas e ramos, o que proporciona maior capacidade de restaurar o vigor vegetativo do cafeeiro, conforme observado por Rena et al. (1983) apud Abreu et al. (2005).

\section{Número de nós do ramo plagiotrópico}

A característica número de nós é um bom indicador da quantidade disponível de gemas produtivas, já que é considerado um dos principais componentes de produtividade (Bonomo et al., 2004).

Assim como para diâmetro de copa, verificouse efeito significativo $(\mathrm{P}<0,01)$ do desdobramento tipos de podas em todas as épocas avaliadas para a característica número de nós do ramo plagiotrópico. Neste caso também ficou evidenciado que o modelo linear ajustou-se a todos os tratamentos com coeficientes de determinação superiores a 0,88 (Figura 2).

Figura 2. Número de nós do ramo plagiotrópico de plantas da cultivar Mundo Novo submetidas a três tipos de poda na Região do Alto Paranaíba, 2016.

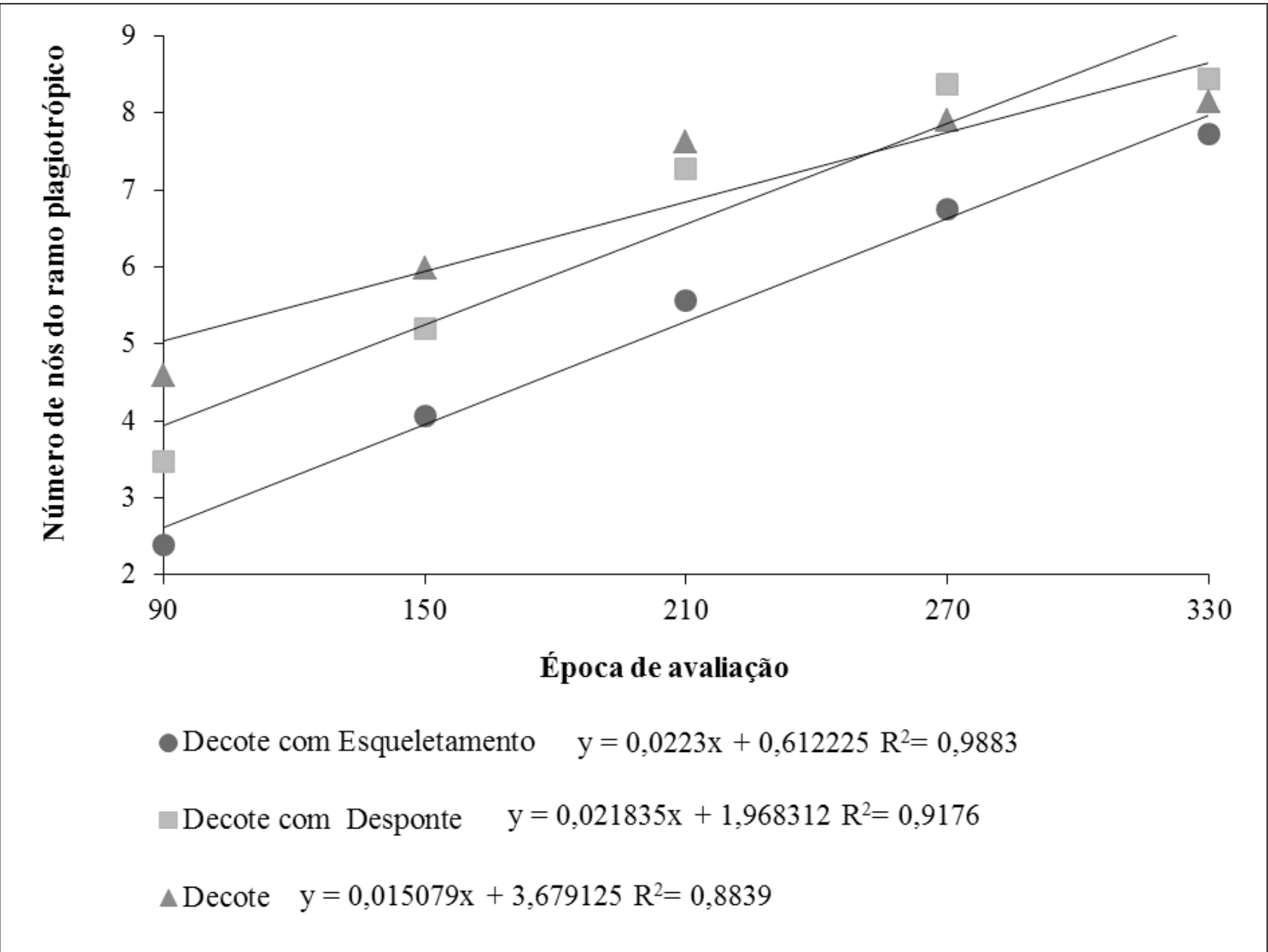


De forma semelhante ao diâmetro de copa aos 90 dias após a poda, as plantas submetidas ao decote apresentaram maior quantidade de nós quando comparado com as plantas decotadas com desponte e decotadas com esqueletamento. Na segunda época de avaliação foi possível observar crescimento similar entre as plantas decotadas e as decotadas com desponte, havendo diferença somente nas plantas decotadas com esqueletamento que apresentavam valores inferiores com relação ao número de nós. Aos 270 dias observouse que as plantas decotadas com desponte superaram as plantas que receberam somente 0 decote.

A cada 100 dias após a poda é possível estimar por meio da inclinação das retas ajustadas que houve um crescimento de 2,23 e 2,18 nós nas plantas submetidas ao decote com esqueletamento e decote com desponte, respectivamente. Já para as plantas submetidas ao decote 0 crescimento foi de 1,51 nós a cada 100 dias.

Plantas submetidas a podas menos drásticas (Decote e Decote com desponte) apresentaram uma evolução no crescimento superior às plantas submetidas ao decote com esqueletamento para a característica número de nós do ramo plagiotrópico. Esses resultados confirmam os encontrados por Fernandes et al. (2012), que verificaram que quanto mais drástica for a poda maior será o tempo para a recuperação da planta. Segundo Thomaziello e Pereira (2008) a quantidade de parte aérea eliminada está relacionada ao número de raízes mortas. Assim, com a adoção de podas menos drásticas, a porcentagem de raízes vivas são maiores, refletindo em maior desenvolvimento e consequentemente maiores produtividades.

\section{Comprimento do ramo plagiotrópico}

Analisando 0 comprimento do ramo plagiotrópico, verificou-se efeito significativo do desdobramento tipo de podas em todas as épocas avaliadas $(P<0,01)$. 0 comprimento do ramo plagiotrópico do cafeeiro ajustou-se ao modelo linear em todos os tratamentos com coeficientes de determinação superiores a 0,88 (Figura 3).

Figura 3. Comprimento de ramo plagiotrópico de plantas da cultivar Mundo Novo submetidas a três tipos de poda na Região do Alto Paranaíba, 2016.

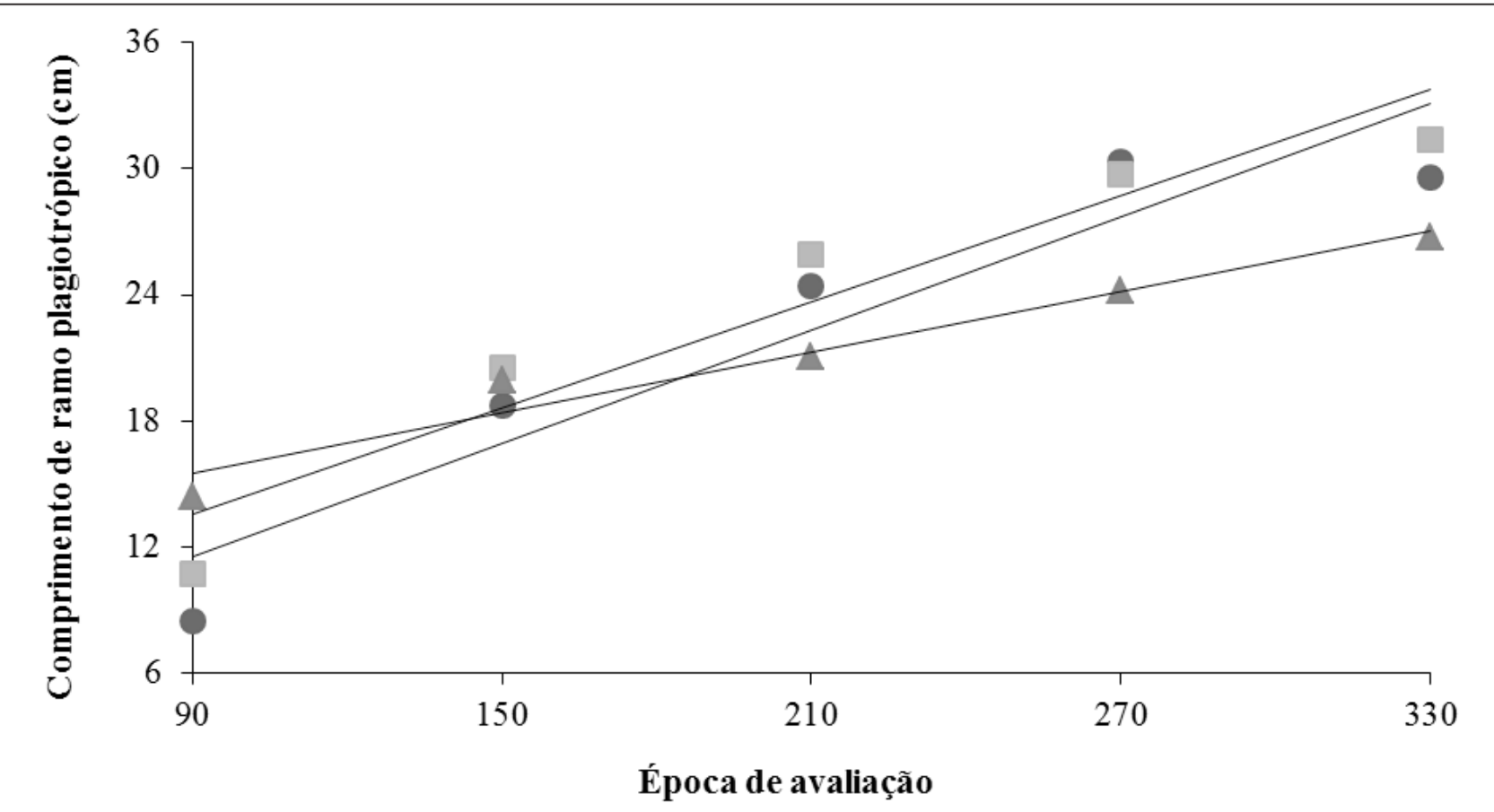

Decote com Esqueletamento $\quad \mathrm{y}=0,089613 \mathrm{x}+0,00467567 \mathrm{R}^{2}=0,8897$

Decote com Desponte $y=0,084175 x+0,00467567 R^{2}=0,9155$

$\Delta$ Decote $\mathrm{y}=0,048006 \mathrm{x}+0,00467567 \mathrm{R}^{2}=0,9579$ 
Pode-se estimar, por meio da inclinação das retas ajustadas, que, para cada 100 dias após a poda houve um acréscimo de 4,8; 8,4 e 8,9 cm no comprimento de ramo plagiotrópico, respectivamente, para as podas decote, decote com desponte e decote com esqueletamento.

Para a primeira época de avaliação as plantas submetidas ao decote e decote com desponte apresentaram comportamento semelhante, havendo diferença entre essas podas e 0 decote com esqueletamento. As plantas submetidas ao decote com desponte se mostraram superiores aos 210 dias após a poda, não havendo diferenças entre as podas de decote e decote com esqueletamento. Com relação à última época de avaliação, fol observada uma tendência de convergência do comprimento de ramo das plantas submetidas ao decote com desponte e decote com esqueletamento, sendo que plantas decotadas apresentaram menor comprimento de ramo.

Um maior crescimento dos ramos plagiotrópicos nas plantas onde foi realizada a poda dos mesmos (decote com desponte e decote com esqueletamento) pode indicar que a poda foi realizada no momento em que as plantas necessitavam da poda dos ramos plagiotrópicos, pois as plantas somente decotadas apresentaram menor crescimento dos ramos plagiotrópicos.

A condição em que a planta se encontra no momento da poda e a escolha do tipo de poda que será aplicada são fatores de grande importância que devem ser considerados na realização desse trato cultural. Podas realizadas em plantas que não possuem boa capacidade de recuperação natural podem ocasionar prejuízos ao produtor. Em estudos conduzidos por Matiello et al. (2006), foi possível afirmar após três safras que o uso do esqueletamento não apresentou vantagem em relação a testemunha sem 0 uso de podas, devido a lavoura apresentar boa capacidade produtiva e não estar no momento adequado para realização da poda.

\section{Tempo de desbrota}

Para a variável resposta tempo de desbrota foi observado efeito significativo $(P<0,01)$ para o fator sistema de condução. Para os demais fatores e a interação poda versus condução não foi observado efeito significativo a $5 \%$ de probabilidade (Tabela 3).

Tabela 3. Resumo da análise de variância para tempo de desbrota de plantas do cultivar Mundo Novo submetido a três tipos de poda e dois sistemas de condução dos brotos na Região do Alto Paranaíba, 2016

\begin{tabular}{ccc}
\hline FV & GL & Quadrados médios \\
\cline { 3 - 3 } & 2 & Tempo de desbrota \\
\hline Poda (P) & 1 & $21857,62^{\text {ns }}$ \\
Condução $(\mathrm{C})$ & 2 & $2469775,04^{* *}$ \\
P x C & 3 & $9741,29^{\text {ns }}$ \\
Bloco & 15 & 1469,59 \\
Erro & & 6932,86 \\
\hline CV (\%) & & 10,21 \\
\hline Média & & 815,13 \\
\hline
\end{tabular}

ns Não significativo, ${ }^{* *}$ Significativo a $1 \%$ de probabilidade pelo teste $\mathrm{F}$.

Os dados analisados demonstram o menor tempo para se realizar a desbrota nas plantas conduzidas com desbrota química. As plantas submetidas à desbrota química demandaram $229,6 \%$ menos tempo quando comparado com a desbrota manual. Isto pode ser justificado devido a quantidade de ramos "ladrões" desbrotados manualmente ser maior, pois, na condução com desbrota química não são retirados os ramos "ladrões" do terço superior do ramo ortotrópico (Tabela 4). 
Tabela 4. Tempo gasto na desbrota de plantas do cultivar Mundo Novo submetidas a dois sistemas de condução dos brotos na Região do Alto Paranaíba, 2016

\begin{tabular}{cc}
\hline Condução & Tempo gasto na desbrota (s) \\
\hline Desbrota Química & $494 \mathrm{a}$ \\
Desbrota Manual & $1136 \mathrm{~b}$
\end{tabular}

Médias seguidas pela mesma letra na coluna não diferem entre si pelo teste $\mathrm{F}$ a $5 \%$ de probabilidade.

O uso de desbrota química é uma técnica recente no cafeeiro. Estudos realizados por Matiello e Jordão Filho (2015) demonstraram que o uso da desbrota química auxilia na redução das brotações pós-poda, oferecendo boa eficiência. Porém, deve-se ter cuidado para que a calda atinja somente o local desejado na planta e que ocorra o mínimo de deriva na pulverização.
Os diferentes tipos de podas não influenciaram no tempo gasto para retirada dos ramos "ladrões" pelo teste de Tukey a $5 \%$ de probabilidade. Este fato pode ser justificado devido as plantas no momento da desbrota apresentarem quantidade similar de ramos "ladrões" devido à exposição do ramo ortotrópico ao sol, considerado um dos fatores que estimulam a brotação nesta parte da planta após a poda (Tabela 5).

Tabela 5. Tempo gasto na desbrota de plantas da cultivar Mundo Novo submetidas a três tipos de podas na Região do Alto Paranaíba, 2016

\begin{tabular}{cc}
\hline Tipos de poda & Tempo gasto na desbrota (s) \\
\hline Decote & $819 \mathrm{a}$ \\
Decote com Desponte & $865 \mathrm{a}$ \\
Decote com Esqueletamento & $760 \mathrm{a}$ \\
\hline
\end{tabular}

Médias seguidas pela mesma letra na coluna não diferem entre si pelo teste de Tukey a $5 \%$ de probabilidade.

\section{Produtividade e rendimento}

De acordo com a análise de variância não foi observado efeito significativo das podas e conduções utilizadas, bem como a interação entre ambas para a característica produtividade. Analisando 0 rendimento (quantidade de litros de café colhido para compor uma saca de $60 \mathrm{~kg}$ de café beneficiado) foi observado efeito significativo $(P<0,01)$ somente para o fator poda (Tabela 6).

Tabela 6. Resumo da análise de variância para produtividade e rendimento (roça/beneficiado) de plantas da cultivar Mundo Novo submetidas a três tipos de poda e dois sistemas de condução dos brotos na Região do Alto Paranaiba, 2017

\begin{tabular}{cccc}
\hline \multirow{2}{*}{ FV } & GL & \multicolumn{2}{c}{ Quadrado médio } \\
\cline { 3 - 4 } & 2 & Produtividade & Rendimento \\
\hline Poda (P) & $339,61^{\text {ns }}$ & $12952,82^{*}$ \\
Condução (C) & 1 & $97,28^{\text {ns }}$ & $126,36^{\text {ns }}$ \\
P x C & 2 & $80,50^{\text {ns }}$ & $31,81^{\text {ns }}$ \\
Bloco & 3 & 145,27 & 217,15 \\
Erro & 15 & 180,57 & 1198,27 \\
\hline CV (\%) & & 13,07 & 6,79 \\
\hline Médias & & 102,77 & 509,93 \\
\hline
\end{tabular}

ns Não significativo, ** Significativo a $1 \%$ de probabilidade pelo teste F. 
0 efeito não significativo observado para produtividade (média de 102,8 sacas ha-1) demonstra que as podas e conduções dos brotos utilizadas não afetaram a quantidade de café beneficiado produzido, sendo que tais práticas podem ser adotadas para recuperação da lavoura sem que haja prejuízo ao produtor com relação à produtividade (Tabelas 7 e 8). Os resultados observados corroboram com os encontrados por Fernandes et al. (2012), onde a utilização ou não de desbrota não influenciou a produtividade. Porém, com relação ao tipo de poda os resultados encontrados divergem, pois os autores desse trabalho demonstraram uma redução na produtividade com adoção de podas mais drásticas (decote com esqueletamento) em relação a uma poda menos drástica (decote com desponte).

Tabela 7. Produtividade e rendimento roça/beneficiado de plantas da cultivar Mundo Novo submetidas a dois sistemas de condução dos brotos na Região do Alto Paranaíba, 2017

\begin{tabular}{ccc}
\hline Podas & Produtividade (sacas de $60 \mathrm{~kg} \mathrm{ha}^{-1}$ ) & Rendimento roça/beneficiado \\
\hline Decote & $98,4 \mathrm{a}$ & $552,53 \mathrm{a}$ \\
Decote com desponte & $99,6 \mathrm{a}$ & $504,71 \mathrm{~b}$ \\
Decote com esqueletamento & $110,3 \mathrm{a}$ & $472,56 \mathrm{~b}$ \\
\hline
\end{tabular}

Médias seguidas pela mesma letra na coluna não diferem entre si pelo teste de Tukey ao nível de $5 \%$ de probabilidade.

Tabela 8. Produtividade e rendimento roça/beneficiado de plantas da cultivar Mundo Novo submetidas a dois sistemas de condução dos brotos na Região do Alto Paranaíba, 2017

\begin{tabular}{ccc}
\hline Podas & Produtividade (sacas de $60 \mathrm{~kg} \mathrm{ha}^{-1}$ ) & Rendimento roça/beneficiado \\
\hline Desbrota Química & $104,8 \mathrm{a}$ & $512,2 \mathrm{a}$ \\
Desbrota Manual & $100,8 \mathrm{a}$ & $507,6 \mathrm{a}$ \\
\hline
\end{tabular}

Médias seguidas pela mesma letra na coluna não diferem entre si pelo teste de Tukey ao nível de $5 \%$ de probabilidade.

Verificou-se efeito significativo ao nível de $1 \%$ de probabilidade do fator poda de forma isolada para rendimento do café (Tabela 6). A poda do tipo decote proporcionou menor rendimento, sendo necessário maior volume de café colhido na planta para produção de uma saca de $60 \mathrm{~kg}$ de café beneficiado $(552,53 \mathrm{~L}$ saca-1), não havendo diferença significativa entre as podas do tipo decote com desponte e decote com esqueletamento (488,6 L saca-1) (Tabela 7). Uma possível explicação para o maior rendimento de plantas cujos ramos plagiotrópicos foram podados (desponte ou esqueletamento) foi o fato da maior incidência de luz no dossel da planta, proporcionando consequentemente menor percentual de frutos verdes e maior quantidade de frutos secos nestes tratamentos (Tabela 10). Em função do elevado teor de água presente nos frutos verdes (60 a $70 \%$ ), durante a secagem os grãos perdem água e reduzem a massa, sendo necessário um maior volume de café nestas condições para se obter uma saca de $60 \mathrm{~kg}$ de café beneficiado (Bartholo e Guimarães, 1997; Lima et al., 2008).
Para as características produtividade e rendimento, não foram observadas diferenças significativas entre os sistemas de condução de podas utilizados ao nível de $5 \%$ de probabilidade pelo teste $\mathrm{F}$ (Tabela 6). A produtividade de lavoura desbrotada com uso do glifosato foi de 104,8 sacas ha-1, enquanto que na desbrota manual atingiu 100,8 sacas ha-1. Dessa forma, apesar da aplicação do herbicida ocasionar sintomas de toxidez nas plantas aos 30 dias após a aplicação, o cafeeiro conseguiu recuperar e tal fato não comprometeu a produtividade e rendimento da lavoura. Em termos médios, foi necessário um volume de 512,2 L e 507,6 L para compor uma saca de $60 \mathrm{~kg}$ com a desbrota química e manual, respectivamente (Tabela 8).

\section{Maturação}

Com relação ao estádio de maturação dos frutos, observa-se efeito significativo somente para os tipos de podas nos estádios cereja e verde cana a 1\% de probabilidade e passa e seco a $5 \%$ de probabilidade 
$(P<0,05)$ (Tabela 9). Não houve diferença significativa entre os sistemas de condução dos brotos para frutos no estádios verde $(9,6 \%)$, verde cana $(16,8 \%)$, cereja $(36,9 \%)$, passa $(13,0 \%)$ e seco $(23,4 \%)$ (Tabela 11$)$.

Tabela 9. Resumo da análise de variância para percentual de maturação dos frutos de café de plantas da cultivar Mundo Novo submetido a três tipos de poda e dois sistemas de condução dos brotos na Região do Alto Paranaíba, 2017

\begin{tabular}{ccccccc}
\hline \multirow{2}{*}{ FV } & \multirow{2}{*}{ GL } & \multicolumn{5}{c}{ Quadrado médio } \\
\cline { 3 - 6 } & & Verde & Verde Cana & Cereja & Passa & Seco \\
\hline Poda (P) & 2 & $12,81^{\text {ns }}$ & $95,71^{*}$ & $372,09^{* *}$ & $59,76^{*}$ & $545,70^{* *}$ \\
Condução $(\mathrm{C})$ & 1 & $19,65^{n \text { s }}$ & $40,11^{\text {ns }}$ & $144,25^{\text {ns }}$ & $0,19^{\text {ns }}$ & $3,72^{\text {ns }}$ \\
Px C & 2 & $3,22^{\text {ns }}$ & $6,63^{\text {ns }}$ & $39,09^{\text {ns }}$ & $0,62^{\text {ns }}$ & $25,52^{\text {ns }}$ \\
Bloco & 3 & 3,31 & 38,18 & 32,58 & 25,60 & 64,91 \\
Erro & 15 & 7,38 & 22,71 & 37,45 & 14,14 & 55,94 \\
\hline CV (\%) & & 28,28 & 28,36 & 16,59 & 28,93 & 31,92 \\
\hline Médias & & 9,60 & 16,80 & 36,89 & 13,00 & 23,43 \\
\hline
\end{tabular}

ns Não significativo, ${ }^{* *}$ Significativo a $1 \%,{ }^{*}$ Significativo a $5 \%$ de probabilidade pelo teste $\mathrm{F}$.

Tabela 10. Percentual de maturação de frutos de café em função de sistemas de podas no ano de 2017

\begin{tabular}{cccccc}
\hline & \multicolumn{5}{c}{ Médias } \\
\cline { 2 - 6 } Poda & Verde & Verde Cana & Cereja & Passa & Seco \\
\hline Decote & $11,00 \mathrm{a}$ & $20,19 \mathrm{a}$ & $44,72 \mathrm{a}$ & $9,88 \mathrm{~b}$ & $14,03 \mathrm{~b}$ \\
Decote com desponte & $8,54 \mathrm{a}$ & $16,94 \mathrm{ab}$ & $32,24 \mathrm{~b}$ & $15,01 \mathrm{a}$ & $26,72 \mathrm{a}$ \\
Decote com esqueletamento & $9,26 \mathrm{a}$ & $13,27 \mathrm{~b}$ & $33,71 \mathrm{~b}$ & $14,10 \mathrm{ab}$ & $29,53 \mathrm{a}$ \\
\hline
\end{tabular}

Médias seguidas pela mesma letra na coluna não diferem entre si pelo teste de Tukey ao nível de $5 \%$ de probabilidade.

Tabela 11. Percentual de maturação de frutos de café em função de dois sistemas de condução dos brotos na Região do Alto Paranaíba, 2017

\begin{tabular}{cccccc}
\hline & \multicolumn{5}{c}{ Médias } \\
\cline { 2 - 6 } Poda & Verde & Verde Cana & Cereja & Passa & Seco \\
\hline Desbrota Química & $8,70 \mathrm{a}$ & $15,51 \mathrm{a}$ & $39,35 \mathrm{a}$ & $13,09 \mathrm{a}$ & $23,04 \mathrm{a}$ \\
Desbrota Manual & $10,51 \mathrm{a}$ & $18,10 \mathrm{a}$ & $34,44 \mathrm{a}$ & $12,91 \mathrm{a}$ & $23,83 \mathrm{a}$ \\
\hline
\end{tabular}

Médias seguidas pela mesma letra na coluna não diferem entre si pelo teste de Tukey ao nível de $5 \%$ de probabilidade.

O estudo da uniformidade de maturação dos frutos é de extrema importância na cafeicultura, pois a mesma possui relação direta com a qualidade de bebida. Quanto maior a porcentagem de frutos no estádio cereja no momento da colheita, maior a chance de se obter uma qualidade superior na bebida, assim como alta quantidade de frutos verdes proporciona característica adstringente, depreciando a bebida, 0 que acarretará em menor remuneração da saca de café. De forma geral, o estádio de maturação cereja se caracteriza maior atividade da polifenoloxidase e baixa lixiviação de potássio, enquanto que o contrário acontece quando os frutos são colhidos no estádio verde ou seco (Pimenta, Chagas e Costa, 1997). A atividade deste enzima está totalmente relacionada à qualidade da bebida, sendo, portanto, fundamental iniciar a colheita no momento correto, com menor percentual de frutos verdes.

A poda do tipo decote foi a que proporcionou maior porcentagem de frutos verde cana $(20,19 \%)$, significativamente semelhante ao decote com desponte $(16,94 \%)$, diferindo somente do decote com esqueletamento $(13,27 \%)$. Plantas decotadas apresentaram maior percentual de frutos cereja em relação às demais podas utilizadas. Com relação aos frutos secos, os maiores percentuais foram observados 
nas plantas que tiveram os ramos plagiotrópicos podados (média de $28,12 \%$ ) em relação às plantas que foram podadas somente o terço superior do ramo ortotrópico (média de 14,03\%) (Tabela 10).

Com base no estudo realizado, verifica-se que as podas que proporcionaram maior crescimento vegetativo foram as menos drásticas, tais como decote e decote com desponte. 0 uso da desbrota química ocasionou redução no crescimento vegetativo para o diâmetro de copa e comprimento do ramo plagiotrópicos, porém, esses fatores não afetaram a produtividade de café beneficiado.

Com relação ao tempo gasto na operação de desbrota, observou-se um tempo menor de operação quando se empregou a desbrota química, reduzindo a utilização de mão-de-obra e consequentemente o custo de produção.

As podas do tipo decote com desponte e decote com esqueletamento proporcionaram maior rendimento e menor percentual de frutos verdes nas plantas, sendo necessário menor volume de café para se produzir uma saca beneficiada.

\section{REFERÊNCIAS BIBLIOGRÁFICAS}

Abreu, N.A.A.D.; Guimarães, R.J.; Oliveira, A.L.D.; Oliveira, S.D.; Vallone, H.S.; Mendes, A.N.G. Efeito de diferentes épocas nos tipos de podas em lavouras adensadas. In: SIMPÓSIO DE PESQUISADOS CAFÉS DO BRASIL, 4., 2005, Londrina. Anais... Brasília: Embrapa Café, 2005.

Bartholo, G.F.; Guimarães, P.T.G. Cuidados na colheita e preparo do café. Informe Agropecuário, 1997, 18, $187,33-42$.

Bonomo, P.; Cruz, C.D.; Viana, J.M.S.; Pereira, A.A.; Oliveira, V.R. de; Carneiro, P.C.S. Avaliação de progênies obtidas de cruzamentos de descendentes do híbrido de Timor com as cultivares Catuaí Vermelho e Catuaí Amarelo. Bragantia, 2004, 63, 207-2194.

Carvalho, G.R; Figueiredo, T.F.; Carvalho, A.M.; Ferreira, A.D.; Resende, M.R.; Botelho C.E.; Tipos de podas e condução de lavora cafeeira. Belo Horizonte: EPAMIG, 2010.p. 1-2. ISSN 0103-4413. Disponível em :<http://www. epamig.br/index.php?option=com docman\&task=doc download\&gid=1362>. Acesso em: 5 set. 2015.
CONAB - COMPANHIA NACIONAL DE ABASTECIMENTO. Acompanhamento da Safra Brasileira de Café, Primeiro Levantamento, Brasília, p. 1-72, jan. de 2018. Disponível em: <https://www.conab. gov.br/index.php/info-agro/safras/cafe>. Acesso em: 28 abr. 2018.

Fernandes, A.L.T.; Santinato, F.; Santinato, R.; Micchelin, V. Condução das podas do cafeeiro irrigado por gotejamento cultivado no cerrado de Minas Gerais. Enciclopédia biosfera, 2012, 8, 15, 488.

Ferreira, D.F. SISVAR: um programa para análises e ensino de estatística. Revista Symosium, 2008, 6, 1, 36-41.

França, A.C.; Freitas, M.A.M.; D'antonino, L.; Fialho, C.M.T.; Silva, A.A.; Reis, M.R.; Ronchi, C.P. Teores de nutrientes em cultivares de café arabica submetidos à deriva de glyphosate. Planta Daninha, 2010a, 28, 4, 877-885.

França, A.; Freitas, M.; Fialho, C.; Silva, A.; Reis, M.; Galon, L.; Victoria Filho, R. Crescimento de cultivares de café arabica submetidos a doses do glyphosate. Planta Daninha, 2010b, 28, 3, 599-607.

Lima, L.A.; Custódio, A.A.P.; Gomes, N.M. Produtividade e rendimento do cafeeiro nas cinco primeiras safras irrigado por pivô central em Lavras, MG. Ciência e Agrotecnologia, 2008, 32, 1832-1842.

Matiello, J.B.; Ferreira, I.B. Testagem de desbrota química em cafeeiros Conillon. In: CONGRESSO BRASILEIRO DE PESQUISAS CAFEEIRAS, 41. 2015, Poços de Caldas. Anais... Brasília: Embrapa Café, 2015.

Matiello, J.B.; Jordão Filho. Efeito da poda/desbrota química em cafeeiros decotados. In: CONGRESSO BRASILEIRO DE PESQUISAS CAFEEIRAS, 41., 2015,Poços de Caldas. Anais... Brasília: Embrapa Café, 2015.

Matiello, J.B.; Santinato, R.; Garcia, A.W.R.; Alneida, S.R.; Fernades, D.R. Cultura de café no Brasil: Manual de recomendações. Varginha: MAPA/PROCAFÉ, 2010. p 351-379. 
Matiello, J.B.; Garcia, W.R.; Almeida, S.R. A poda em cafezais. Revista Brasileira de Tecnologia Cafeeira, 2007, 4, 11, 10-14.

Matiello, J.B.; Mendonça, S.M; Lopes Filho, S.; Louback, A.S. Clico de poda por esqueletamento e níveis de adubação do cafeeiro. In: CONGRESSO BRASILEIRO DE PESQUISAS CAFEEIRAS, 32., 2006, Poços de Caldas. Anais... Rio de Janeiro: MAPA/Procafé, 2006. p. 6-7.

Pereira, S.P.; Guimarães, R.J.; Bartholo, G.F.; Guimarães, P.T.G.; Alves, J.D. Crescimento vegetativo e produção de cafeeiros (Coffea arabica L.) recepados em duas épocas, conduzidos em espaçamentos crescentes. Ciência e Agrotecnologia, 2007, 31, 3, 643649.
Pimenta, C. J.; Chagas, S.J.R.; Costa, L. Polifenoloxidase, lixiviação de potássio e qualidade de bebida do café colhido em quatro estádios de maturação. Pesquisa Agropecuária Brasileira, 1997, 32, 2, 171-1777.

Sá Júnior, A. de. Aplicação da classificação de Köppen para o zoneamento climático do estado de Minas Gerais. 2009. 101 p. Dissertação (Mestrado em Engenharia Agrícola/Engenharia de Água e Solo) - Universidade Federal de Lavras, Lavras, 2009.

Thomaziello, R.A.; Pereira, S.P. Poda e condução do cafeeiro arábica. Campinas: IAC, 2008. p. 1-30. 